\title{
MONOTONICITY PROPERTIES AND BOUNDS INVOLVING THE COMPLETE ELLIPTIC INTEGRALS OF THE FIRST KIND
}

\author{
Zhen-Hang Yang, Wei-Mao Qian and Yu-Ming Chu
}

Abstract. In the article, we establish several monotonicity properties of the functions involving the complete elliptic integral of the first kind. As applications, we present sharp bounds for the complete elliptic integral of the first kind and the arithmetic-geometric mean.

Mathematics subject classification (2010): 33E05, 26E60.

Keywords and phrases: Complete elliptic integral, Gaussian hypergeometric function, arithmetic-geometric mean.

\section{REFERENCES}

[1] M. Abramowitz And I. A. STEgun, Handbook of Mathematical Functions with Formulas, Graphs and Mathematical Tables, Dover, New York, 1965.

[2] M. Adil Khan, S. Begum, Y. Khurshid and Y.-M. Chu, Ostrowski type inequalities involving conformable fractional integrals, J. Inequal. Appl. 2018 (2018), Article 70, 14 pages.

[3] M. Adil Klan, Y.-M. Chu, T. U. Khan And J. Khan, Some new inequalities of HermiteHadamard type of s-convex functions with applications, Open Math. 15 (2017), 1414-1430.

[4] H. AlzER, Sharp inequalities for the complete elliptic integral of the first kind, Math. Proc. Cambridge Philos. Soc. 124, 2 (1998), 309-314.

[5] H. AlZER AND S.-L. QIU, Monotonicity theorem and inequalities for the complete elliptic integrals, J. Comput. Appl. Math., 172, 2 (2004), 289-312.

[6] H. Alzer AND K. Richards, On the modulus of the Grötzsch ring, J. Math. Anal. Appl. 432, 1 (2015), 134-141.

[7] H. Alzer And K. Richards, Inequalities for the ratio of complete elliptic integrals, Proc. Amer. Math. Soc. 145, 4 (2017), 1661-1670.

[8] G. D. Anderson, S.-L. Qiu and M. K. Vamanamurthy, Elliptic integral inequalities, with applications, Constr. Approx. 14, 2 (1998), 195-207.

[9] G. D. Anderson, S.-L. Qiu, M. K. Vamanamurthy and M. Vuorinen, Generalized elliptic integrals and modular equations, Pacific J. Math. 192, 1 (2000), 1-37.

[10] G. D. Anderson, M. K. Vamanamurthy and M. Vuorinen, Functional inequalities for hypergeometric functions and complete elliptic integrals, SIAM. J. Math. Anal. 23, 2 (1992), 512-524.

[11] G. D. Anderson, M. K. Vamanamurthy and M. Vuorinen, Conformal Invariants, Inequalities, and Quasiconformal Maps, John Wiley \& Sons, New York, 1997.

[12] R. W. BARNARD, K. PEARCE AND K. C. RICHARDS, An inequality involving the generalized hypergeometric function and the arc length of an ellipse, SIAM J. Math. Anal. 31, 3 (2000), 693-699.

[13] J. M. Borwein And P. B. Borwein, Pi and the AGM, John Wiley \& Sons, New York, 1987.

[14] P. BRACKEN, An arithmetic-geometric mean inequality, Expo. Math. 19, 3 (2001), 273-279.

[15] P. F. BYRD AND M. D. Friedman, Handbook of Elliptic Integrals for Engineers and Scientists, Springer-Verlag, New York, 1971.

[16] B. C. CARlson And J. L. Gustafson, Asymptotic expansion of the first elliptic integral, SIAM J. Math. Anal. 16, 5 (1985), 1072-1092.

[17] B. C. CARLSON AND M. VuORINEN, Inequality of the AGM and the logarithmic mean, SIAM Rev. 33, 4 (1991), 653-654. 
[18] Y.-M. ChU And Y.-P. Lv, The Schur harmonic convexity of the Hamy symmetric function and its applications, J. Inequal. Appl. 2009 (2009), Article ID 838529, 10 pages.

[19] Y.-M. CHU, Y.-F. QIU AND M.-K. WANG, Hölder mean inequalities for the complete elliptic integrals, Integral Transforms Spec. Funct. 23, 7 (2012), 521-527.

[20] Y.-M. ChU, S.-L. QIU AND M.-K. WANG, Sharp inequalities involving the power mean and complete elliptic integral of the first kind, Rocky Mountain J. Math. 43, 3 (2013), 1489-1496.

[21] Y.-M. CHU AND T.-C. SUn, The Schur harmonic convexity for a class of symmetric functions, Acta Math. Sci. 30B, 5 (2010), 1501-1506.

[22] Y.-M. ChU AND M.-K. WANG, Optimal Lehmer mean bounds for the Toader mean, Results Math. 61, 3-4 (2012), 223-229.

[23] Y.-M. CHU, M.-K. WANG, Y.-P. JiAnG AND S.-L. QIU, Concavity of the complete elliptic integrals of the second kind with respect to Hölder means, J. Math. Anal. Appl. 395, 2 (2012), 637-642.

[24] Y.-M. ChU, M.-K. WANG AND X.-Y. MA, Sharp bounds for Toader mean in terms of contraharmonic mean with applications, J. Math. Inequal. 7, 2 (2013), 161-166.

[25] Y.-M. ChU, M.-K. WANG AND S.-L. QIU, Optimal combinations bounds of root-square and arithmetic means for Toader mean, Proc. Indian Acad. Sci. Math. Sci. 122, 1 (2012), 41-51.

[26] Y.-M. ChU, M.-K. WANG, S.-L. QIU AND Y.-P. JIANG, Bounds for complete integrals of the second kind with applications, Comput. Math. Appl. 63, 7 (2012), 1177-1184.

[27] Y.-M. ChU, M.-K. WAng, S.-L. QIU AND Y.-F. QIU, Sharp generalized Seiffert mean bounds for Toader mean, Abstr. Appl. Anal. 2011 (2011), Article ID 605259, 8 pages.

[28] Y.-M. ChU, G.-D. WANG AND X.-H. ZHAng, Schur convexity and Hadamard's inequality, Math. Inequal. Appl. 13, 4 (2010), 725-731.

[29] Y.-M. ChU, G.-D. WANG AND X.-H. ZHANG, The Schur multiplicative and harmonic convexities of the complete symmetric function, Math. Nachr. 284, 5-6 (2011), 653-663.

[30] Y.-M. CHU AND W.-F. XIA, Two sharp inequalities for power mean, geometric mean, and harmonic mean, J. Inequal. Appl. 2009 (2009), Article ID 741923, 6 pages.

[31] Y.-M. ChU AND W.-F. XIA, Inequalities for generalized logarithmic means, J. Inequal. Appl. 2009 (2009), Article ID 763252, 7 pages.

[32] Y.-M. ChU AND W.-F. XIA, Solution of an open problem for Schur convexity or concavity of the Gini mean calues, Sci. China 52A, 10 (2009), 2099-2106.

[33] Y.-M. CHU AND W.-F. XIA, Two optimal double inequalities between power mean and logarithmic mean, Comput. Math. Appl. 60, 1 (2010), 83-89.

[34] Y.-M. ChU, W.-F. XIA AND X.-H. ZHANG, The Schur convexity, Schur multiplicative and harmonic convexities of the second dual form of the Hamy symmetric function with applications, J. Multivariate Anal. 105 (2012), 412-421.

[35] Y.-M. ChU, W.-F. Xia And T.-H. ZhaO, Schur convexity for a class of symmetric functions, Sci. China Math. 53, 2 (2010), 465-474.

[36] Y.-M. ChU, W.-F. XIA AND T.-H. ZHAO, Some properties for a class of symmetric functions and applications, J. Math. Inequal. 5, 1 (2011), 1-11.

[37] Y.-M. ChU AND X.-M. ZHANG, Necessary and sufficient conditions such that extended mean values are Schur-convex or Schur-concave, J. Math. Kyoto Univ. 48, 1 (2008), 229-238.

[38] Y.-M. Chu, X.-M. Zhang And G.-D. WANG, The Schur geometrical convexity of of the extended mean values, J. Convex Anal. 15, 4 (2008), 707-718.

[39] H. KaZI AND E. Neuman, Inequalities and bounds for elliptic integrals, J. Approx. Theory 146, 2 (2007), 212-226.

[40] H. KaZI AND E. Neuman, Inequalities and bounds for elliptic integrals II, in: Special Functions and Orghogonal Polynomials, 127-138, Contemp. Math., 471, Amer. Math. Soc., Providence, RI, 2008.

[41] R. Kühnau, Eine Methode, die Positivität einer Funktion zu prüfen, Z. Angew. Math. Mech. 74 (1994), 140-143.

[42] Y.-M. LI, W.-F. XIA, Y.-M. ChU AND X.-H. Zhang, Optimal lower and upper bounds for the geometric convex combination of the error function, J. Inequal. Appl. 2015 (2015), Article 382, 8 pages.

[43] E. Neuman, Bounds for symmetric elliptic integrals, J. Approx. Theory 122, 2 (2003), 249-259.

[44] E. Neuman, Inequalities for weighted sums of powers and their applications, Math. Inequal. Appl. 15, 4 (2012), 995-1005. 
[45] E. Neuman And J. SÁndor, On certain means of two arguments and their extension, Int. J. Math. Sci. 16 (2003), 981-993.

[46] F. W. J. Olver, D. W. Lozier, R. F. Boisvert and C. W. Clark, NiSt Digital Library of Mathematical Functions, available onlin at http://dlmf .nist.gov.

[47] F. QI, Bounds for the ratio of two gamma functions, J. Inequal. Appl. 2010 (2010), Article ID 493058, 84 pages.

[48] W.-M. QIAN AND Y.-M. CHU, Sharp bounds for a special quasi-arithmetic mean in terms of arithmetic and geometric means with two parameters, J. Inequal. Appl. 2017 (2017), Article 274, 10 pages.

[49] S.-L. QiU And M. K. VAmanamurthy, Sharp estimates for complete elliptic integrals, SIAM. J. Math. Anal. 27, 3 (1996), 823-834.

[50] S.-L. QIU AND M. VUORINEN, Duplication inequalities for the ratios of hypergeometric functions, Forum Math. 12, 1 (2000), 109-133.

[51] J. SÁnDOR, On certain inequalities for means, J. Math. Anal. Appl. 189, 2 (1995), 602-606.

[52] J. SÁndor, On certain inequalities for means II, J. Math. Anal. Appl. 199, 2 (1996), 629-635.

[53] J. SÁNDOR, On certain inequalities for means III, Arch. Math. 76, 1 (2001), 34-40.

[54] K. B. Stolarsky, Generalizations of the logarithmic mean, Math. Mag. 48 (1975), 87-92.

[55] GH. ToAder, Some mean values related to the arithmetic-geometric mean, J. Math. Anal. Appl. 218, 2 (1998), 358-368.

[56] M. K. Vamanamurthy and M. Vuorinen, Inequalities for Means, J. Math. Anal. Appl. 183, 1 (1994), 155-166.

[57] M.-K. WANG AND Y.-M. CHU, Refinements of transformation inequalities for zero-balanced hypergeometric functions, Acta Math. Sci. 37B, 3 (2017), 607-622.

[58] M.-K. WANG AND Y.-M. CHU, Landen inequalities for a class of hypergeometric functions with applications, Math. Inequal. Appl. 21, 2(2018), 521-537.

[59] M.-K. WANG, Y.-M. CHU AND Y.-P. JiAng, Ramanujan's cubic transformation inequalities for zero-balanced hypergeometric functions, Rocky Mountain J. Math. 46, 2 (2016), 679-691.

[60] M.-K. Wang, Y.-M. Chu And S.-L. QIU, Some monotonicity properties of generalized elliptic integrals with applications, Math. Inequal. Appl. 16, 3 (2013), 671-677.

[61] M.-K. WANG, Y.-M. CHU AND S.-L. QIU, Sharp bounds for generalized elliptic integrals of the first kind, J. Math. Anal. Appl. 429, 2 (2015), 744-757.

[62] M.-K. WAng, Y.-M. ChU, Y.-F. QIU AND S.-L. QIU, An optimal power mean inequality for the complete elliptic integrals, Appl. Math. Lett. 24, 6 (2011), 887-890.

[63] M.-K. Wang, Y.-M. Chu And Y.-Q. Song, Asymptotical formulas for Gaussian and generalized hypergeometric functions, Appl. Math. Comput. 276 (2016), 44-60.

[64] M.-K. WANG, Y.-M. Li AND Y.-M. CHU, Inequalities and infinite product formula for Ramanujan generalized modular equation function, Ramanujan J. 46, 1 (2018), 189-200.

[65] M.-K. WANG, S.-L. QIU AND Y.-M. CHU, Infinite series formula for Hübner upper bounds founction with applications to Hersch-Pfluger distortion function, Math. Inequal. Appl. 21, 3 (2017), 629648.

[66] G.-D. WANG, X.-H. Zhang And Y.-M. CHU, A power mean inequality involving the complete elliptic integrals, Rocky Mountain J. Math. 44, 5 (2014), 1661-1667.

[67] W.-F. XIA AND Y.-M. CHU, Schur-convexity for a class of symmetric functions and its applications, J. Inequal. Appl. 2009 (2009), Article ID 493759, 15 pages.

[68] W.-F. XIA AND Y.-M. CHU, The Schur convexity of Gini mean values in the sense of harmonic mean, Acta Math. Sci. 31B, 3 (2011), 1103-1112.

[69] W.-F. XIA AND Y.-M. CHU, Optimal inequalities between Neuman-Sándor, centroical and harmonic means, J. Math. Inequal. 7, 4 (2013), 593-600.

[70] W.-F. XIA AND Y.-M. CHU, Optimal inequalities for the convex combination of error function, J. Math. Inequal. 9, 1 (2015), 85-99.

[71] W.-F. XIA, Y.-M. CHU AND G.-D. WANG, The optimal upper and lower power mean bounds for a convex combination of the arithmetic and logarithmic means, Abstr. Appl. Anal. 2010 (2010), Article ID 604804, 9 pages.

[72] W.-F. XIA, W. JANOUS AND Y.-M. CHU, The optimal convex combination bounds of arithmetic and hamronic means in terms of power mean, J. Math. Inequal. 6, 2 (2012), 241-248.

[73] W.-F. XiA, X.-H. Zhang, G.-D. WANG AND Y.-M. CHU, Some properties for a class of symmetric functions with applications, Indian J. Pure Appl. Math. 43, 3 (2012), 227-249. 
[74] ZH.-H. YAng AND Y.-M. CHU, Asymptotic formulas for gamma function with applications, Appl. Math. Comput. 270 (2015), 665-680.

[75] ZH.-H. YANG AND Y.-M. CHU, A monotonicity property involving the generalized elliptic integral of the first kind, Math. Inequal. Appl. 20, 3(2017), 729-735.

[76] ZH.-H. YANG, Y.-M. CHU AND W. ZHANG, Accurate approximations for the complete elliptic integrals of the second kind, J. Math. Anal. Appl. 438, 2 (2016), 875-888.

[77] Zh.-H. YAng, Y.-M. ChU AND X.-H. Zhang, Sharp Stolarsky mean bounds for the complete elliptic integral of the second kind, J. Nonlinear Sci. Appl. 10, 3 (2017), 929-936.

[78] ZH.-H. YANG, W.-M. QIAN AND Y.-M. CHU, On rational bounds for the gamma function, J. Inequal. Appl. 2017 (2017), Article 210, 17 pages.

[79] ZH.-H. YANG, W.-M. QIAN, Y.-M. ChU AND W. ZHANG, On approximating the error function, Math. Inequal. Appl. 21, 2 (2018), 469-479.

[80] Zh.-H. Yang, W.-M. QIAN, Y.-M. Chu And W. Zhang, On approximating the arithmeticgeometric mean and complete elliptic integral of the first kind, J. Math. Anal. Appl. 462, 2 (2018), $1714-1726$.

[81] ZH.-H. YANG, Y.-Q. Song AND Y.-M. CHU, Sharp bounds for the arithmetic-geometric mean, J. Inequal. Appl. 2014 (2014), Article 192, 13 pages.

[82] ZH.-H. YANG, W. Zhang AND Y.-M. ChU, Sharp Gautschi inequality for parameter $0<p<1$ with applications, Math. Inequal. Appl. 20, 4 (2017), 1107-1120.

[83] X.-H. Zhang, G.-D. WANG AND Y.-M. ChU, Convexity with respect to Hölder mean involving zero-balanced hypergeometric functions, J. Math. Anal. Appl. 353, 1 (2009), 256-259.

[84] T.-H. ZHAO AND Y.-M. CHU, A class of logarithmically completely monotonic functions associated with a gamma function, J. Inequal. Appl. 2010 (2010), Artilce ID 392431, 11 pages.

[85] T.-H. ZhaO, Y.-M. ChU AND Y.-P. JIANG, Monotonic and logarithmically convex properties of a function involving gamma functions, J. Inequal. Appl. 2009 (2009), Article ID 72861, 13 pages. 